\title{
Nocturnal hypoglycaemia and sleep disturbances in young teenagers with insulin dependent diabetes mellitus
}

Princess Margaret Hospital for Children, Perth, Western Australia:

Department of

Paediatrics

P A Porter

Paediatric

Endocrinology

G Byrne

$\mathrm{T}$ W Jones

Paediatric Respiration and Sleep

S Stick

Correspondence to: Dr Paul A Porter, Chief Registrar (Paediatrics), Princess Margaret Hospital for Children, PO Box D184, Perth 6008, Western Australia.

Accepted 9 April 1996

\author{
Paul A Porter, Geoffrey Byrne, Stephen Stick, Timothy W Jones
}

\begin{abstract}
Objective-To determine the effect of nocturnal hypoglycaemia on sleep architecture in adolescents with insulin dependent diabetes mellitus (IDDM).

Design-20 adolescents with IDDM (mean age 12.8 years, mean glycated haemoglobin $\left(\mathrm{HbA}_{1 \mathrm{c}}\right) \mathbf{8 . 9 \%}$ ) were studied on one night. Plasma glucose was measured every 30 minutes and cortisol and growth hormone levels every 60 minutes. Sleep was recorded using standard polysomnographic montages, and sleep architecture was analysed for total sleep time, stages $1-4$, rapid eye movement, fragmentation, and arousals.

Results-Six subjects (30\%) became hypoglycaemic (five subjects $<2.5 \mathrm{mmol} / \mathrm{l}$ ), with one being symptomatic. There were no differences in age, $\mathbf{H b A}_{1 \mathrm{c}}$, duration of diabetes, or insulin regimen between hypoglycaemic and non-hypoglycaemic subjects. Hypoglycaemia was not predicted by glucose measurements before bed. There was no detectable rise in plasma cortisol or growth hormone concentrations during hypoglycaemia. Sleep architecture was not disturbed by nocturnal hypoglycaemia with no differences found in sleep stages, fragmentation, or arousals.
\end{abstract}

Conclusions-Nocturnal hypoglycaemia is a common and usually asymptomatic complication of treatment in adolescents with IDDM. Moderate hypoglycaemia has not been shown to affect sleep architecture adversely. These findings are consistent with, and may explain, the observation that severe hypoglycaemia, with consequent seizure activity, is more common at night than during the day. Counterregulatory hormone responses to nocturnal hypoglycaemia may be less marked than with similar degrees of diurnal hypoglycaemia.

(Arch Dis Child 1996;75:120-123)

Keywords: insulin dependent diabetes mellitus, nocturnal hypoglycaemia, sleep architecture.

Hypoglycaemia, the most frequent complication of insulin dependent diabetes mellitus (IDDM) in children, is associated with both short and long term sequelae and often limits attempts to improve glycaemic control. ${ }^{1-4}$ Severe hypoglycaemia, as evidenced by seizure activity, is more common at night. In addition, nocturnal hypoglycaemia has been shown to be frequently asymptomatic in adults, while in children biochemically significant nocturnal hypoglycaemia is estimated to occur in between 14 and 35 per cent of children per year. ${ }^{5-10}$

Hypoglycaemia during sleep in adults has been reported both to increase and decrease counterhormonal responsiveness, suggesting physiological differences dependent upon sleep state. ${ }^{11} 12$ Sleep architecture has been examined in adults with IDDM, with prolongation of rapid eye movement cycles and EEG changes (increased $\theta$ and $\delta$ activity) being found during hypoglycaemia. ${ }^{13-15}$

The technology for accurately monitoring sleep architecture (sleep stages, fragmentation, arousals) in children is now well established. It has been shown that sleep fragmentation is associated with daytime somnolence in children and can cause behavioural disturbances. ${ }^{1617}$ Despite this there are few data on the effect of diabetes, alterations in nocturnal glycaemic levels, or hypoglycaemia on either sleep patterns or the electroencephalogram (EEG) in children.

In view of the move towards improved glycaemic control in childhood diabetes following the recommendations of the diabetic control and complications trial (DCCT), it is likely that both the incidence and severity of hypoglycaemia during childhood will increase. ${ }^{18}$ The purpose of this study therefore was to examine sleep architecture in children with IDDM during hypoglycaemia at night and to characterise any sleep disturbance that such hypoglycaemia may cause.

\section{Methods}

SUBJECTS

We studied 20 adolescents, 11 girls and nine boys, between the ages of 11.5 and 14.5 years, mean 12.8 (SD 1) year, attending the diabetes clinic at Princess Margaret Hospital for Children, Perth. Each subject was recruited following informed consent and individual agreement to participate in the study. Ethics approval was obtained from the ethics advisory committee of Princess Margaret Hospital.

The mean duration of diabetes was 4.4 years (range 1 to 10), the mean insulin dose was 0.96 units/kg (range 0.6 to 1.3 ), and the mean glycated haemoglobin $\left(\mathrm{HbA}_{1 \mathrm{c}}\right)$ was $8.9(1) \%$, with a range of 6.5 to 10.2 . Nineteen of the subject group completed the whole pro- 
Table 1 Clinical characteristics of the children who became hypoglycaemic (plasma glucose $<3.5 \mathrm{mmol} / \mathrm{l})$ and those who did not. Values are mean (SD)

\begin{tabular}{lcc}
\hline & Plasma glucose & \\
\cline { 2 - 3 } & $<3.5$ mmoll & $>3.5$ mmoll \\
\hline Age (years) & $12.9(1.1)$ & $12.8(1.0)$ \\
Weight $(\mathrm{kg})$ & $45.8(4.1)$ & $49.03(3.2)$ \\
Height (cm) & $151.8(4.2)$ & $153.7(7.8)$ \\
$\mathrm{HbA}_{1 \mathrm{c}}(\%)$ & $8.8(1.2)$ & $8.9(1.1)$ \\
Duration of diabetes (years) & $4.4(1.5)$ & $4.5(3.2)$ \\
Insulin dose (U/kg) & $0.98(0.15)$ & $0.93(0.2)$
\end{tabular}

No statistical differences between groups.

gramme, with one subject withdrawing because of a painful intravenous catheter site.

PROCEDURE

Each subject was admitted on the evening of the study after having had a normal day's activity, dietary intake (including the evening meal), and insulin dose. On arrival in the sleep unit, EMLA cream (topical anaesthetic) was applied to allow the painless insertion of an intravenous catheter used to take blood specimens during the study. Blood was collected at the time of catheterisation for measurement of glycosylated haemoglobin, every 30 minutes overnight for measurement of glucose, and hourly for cortisol and growth hormone levels.

\section{DETERMINATIONS}

Plasma glucose was measured using a Kodak Ektachem 500 analyser, plasma cortisol and growth hormone concentrations were measured with a Cirrus Immulite analyser, and the $\mathrm{HbA}_{1 \mathrm{c}}$ with a DCA 2000 analyser from Beyer Diagnostics (non-diabetic reference range $<6.2 \%$ ).

\section{SLEEP ANALYSIS}

Sleep variables were recorded by a polysomnograph using standard electroencephalographic, electro-oculographic, electromyelographic, electrocardiographic, oximetry, and respiratory channels. Sleep was scored according to standard criteria as wakefulness, sleep stages $1-4$, and rapid eye movement (REM) sleep. ${ }^{19}$ The percentage of total sleep that was fragmented-defined as having two or more changes in sleep stage per 10 minute intervalwas calculated, as were the number of arousals, defined according to American Sleep Disorders Association guidelines. ${ }^{20}$ Heart rates were monitored continuously and averaged over 30 seconds.

STATISTICAL ANALYSIS

Analysis of the sleep patterns was performed off line by an observer (SS) blinded to the subjects' glycaemia level. Other variables reported

Table 3 Comparison in overnight cortisol and growth hormone levels between the children who became hypoglycaemic and those who did not

\begin{tabular}{llll}
\hline & & $\begin{array}{l}\text { Hypoglycaemic } \\
\text { children }\end{array}$ & $\begin{array}{l}\text { Non-hypoglycaemic } \\
\text { children }\end{array}$ \\
\hline $\begin{array}{l}\text { Cortisol } \\
(\mathrm{nmol} / \mathrm{)})\end{array}$ & Maximum increment from baseline & 464 & 413 \\
& Mean value & 213 & 151 \\
$\begin{array}{c}\text { Growth hormone } \\
(\mathrm{mU} / \mathrm{l})\end{array}$ & Maximum increment from baseline & 40.5 & 41 \\
& Mean value & 19 & 21 \\
\hline
\end{tabular}

No statistical differences between groups.
Table 2 Nocturnal plasma glucose profiles (mmol/l) in children experiencing nocturnal hypoglycaemia

\begin{tabular}{lllll}
\hline & Time & & & \begin{tabular}{l} 
Nadir of \\
plasma glucose \\
\cline { 2 - 5 } (time)
\end{tabular} \\
\hline 2200 & 0200 & 0700 & 7.3 & $2.3(0100)$ \\
Subject 1 & 4.6 & 3.3 & $3.3(0530)$ \\
Subject 2 & 12.8 & 4.7 & 3.4 & $3.3(0230)$ \\
Subject 3 & 9.7 & 2.7 & 3.1 & $2.3(0230)$ \\
Subject 4 & 3.7 & 8.1 & 9.5 & $2.1(2230)$ \\
Subject 5 & 5.6 & 3.3 & 4.5 & $2.5(0300)$ \\
Subject 6 & 13 & 4.2 & 4.1 & $2.5(0330)$ \\
\hline
\end{tabular}

were compared by Student's $t$ tests and the Mann-Whitney test.

\section{Results}

GLUCOSE PROFILES

Hypoglycaemia was defined as a plasma glucose concentration below $3.5 \mathrm{mmol} / \mathrm{l}$ based on studies reporting adrenaline responses and increased hypoglycaemic symptom scores at this level of hypoglycaemia in non-diabetic adolescents. ${ }^{2122}$ Six children (30\%)-three boys and three girls-developed hypoglycaemia during the study and of these five had plasma glucose values below $2.5 \mathrm{mmol} / 1$. There were no differences in age, sex, duration of diabetes, insulin dose, or $\mathrm{HbA}_{1 \mathrm{c}}$ concentrations between those children who were hypoglycaemic and those who were not (table 1). The glycaemic profiles of the children who were hypoglycaemic are shown in table 2.

Hypoglycaemia was often prolonged, with mean duration of 3.96 hours (range 1 to 7 hours). Plasma glucose concentrations taken before sleep were not reliable predictors of subsequent hypoglycaemia; however, the prebreakfast plasma glucose concentrations were significantly lower in the group who had become hypoglycaemic than in the group who did not (mean plasma glucose $5.3 v 11.3$ $\mathrm{mmol} / \mathrm{l}, \mathrm{p}<0.002)$. Mean rise from the nadir plasma glucose concentration to the prebreakfast level was $2.9 \mathrm{mmol} / \mathrm{l}$.

There were no significant differences in total output (as measured hourly), peak level, or maximum increment of increase of plasma cortisol or growth hormone between the two groups (table 3 ). The expected early morning rise in plasma cortisol was observed in all patients. Growth hormone concentrations varied markedly, both between individuals and in the same individual, and were unrelated to glycaemic levels.

SYMPTOMS AND CLINICAL MEASUREMENTS

One child reported subjective symptoms of hypoglycaemia (hunger) at a plasma glucose concentration of $2.1 \mathrm{mmol} / \mathrm{l}$

Heart rates were recorded continuously during the study and expressed in 30 second averages. There were no rises in heart rate during hypoglycaemia in any child. In four of the children who became hypoglycaemic, the heart rates were lower at the nadir of the plasma glucose concentrations than during preceding euglycaemia (mean fall 9.25 beats $/ \mathrm{min}$ ). The remaining two hypoglycaemic children's heart rates remained stable. 
Table 4 Sleep outcome in hypoglycaemic children (plasma glucose $<3.5 \mathrm{mmol} / \mathrm{l}$ ) compared to non-hypoglycaemic subjects. Values are mean (with $95 \%$ confidence intervals)

\begin{tabular}{lll}
\hline & \multicolumn{1}{l}{ Plasma glucose } & \\
\cline { 2 - 3 } & $<3.5 \mathrm{mmoll}$ & $>3.5 \mathrm{mmol} / \mathrm{l}$ \\
\hline Wakefulness $(\%)$ & $12.7(7.8$ to 17.6$)$ & $9.6(6.7$ to 12.5$)$ \\
Stage 1 $(\%)$ & $10(5.6$ to 14.4$)$ & $9.5(5.9$ to 13.1$)$ \\
Stage 2 $(\%)$ & $43.6(44.6$ to 52.6$)$ & $48(44.1$ to 51.7$)$ \\
Stage 3 $(\%)$ & $7.6(6.1$ to 9.1$)$ & $7(4.9$ to 9.1$)$ \\
Stage 4 $(\%)$ & $9.7(7.3$ to 12.1$)$ & $9.1(4.5$ to 13.7$)$ \\
REM (\%) & $15.6(11.1$ to 20.1$)$ & $16.1(12.2$ to 20.0$)$ \\
Percentage total & $33.8(29.5$ to 38.1$)$ & $37.3(34.4$ to 41.2$)$ \\
$\quad$ sleep fragmented & $25.8(23.1$ to 28.5$)$ & $29.8(26.5$ to 33.2$)$ \\
Arousals (total) & 0.051 & 0.059
\end{tabular}

No statistical differences between groups.

Table 5 Comparison of sleep values during hypoglycaemia and euglycaemia. Values are mean (with $95 \%$ confidence intervals)

\begin{tabular}{lll}
\hline & \multicolumn{1}{c}{ Plasma glucose } & $>3.5$ mmoll \\
\cline { 2 - 3 } & $<3.5 \mathrm{mmoll}$ & $40.6(35.4$ to 45.8$)$ \\
\hline $\begin{array}{l}\text { Percentage total sleep } \\
\text { fragmented }\end{array}$ & $33.8(29.5$ to 38.1$)$ & $14.2(12.1$ to 16.3$)$ \\
$\begin{array}{l}\text { Arousals (total) } \\
\text { Arousals/min }\end{array}$ & $11.6(9.2$ to 14.0$)$ & 0.05 \\
\hline
\end{tabular}

No statistical differences between groups.

\section{SLEEP ANALYSIS}

Sleep analysis performed to compare the hypoglycaemic group to the non-hypoglycaemic group is shown in table 4 . No significant differences were found in total sleep time, stages 1-4, REM, percentage of total sleep fragmented, or the number of arousals. A difference was found in the amount of wakefulness, with the hypoglycaemic group being awake longer than the non-hypoglycaemic group; however, this difference is explained by the child who felt hungry while hypoglycaemic and was subsequently awake for 90 minutes. If this child is excluded from the analysis there were no statistically significant differences between the two groups in sleep outcome variables. Further analysis of the hypoglycaemic group as a whole revealed no difference in the percentage of sleep fragmentation or the number of arousals experienced during the periods of hypoglycaemia and the rest of the night (table 5). To exclude the possibility that blood sampling may have disturbed the children, sleep was analysed and compared for the 10 minutes directly before sampling and for the 10 minutes directly after sampling. There were no differences in either the total percentage of sleep fragmentation or the number of arousals during these times.

\section{Discussion}

In this study we have shown a high frequency of asymptomatic nocturnal hypoglycaemia occurring in adolescents with IDDM. This group was representative of our young adolescent diabetic population in that the $\mathrm{HbA}_{1 \mathrm{c}}$ concentrations in the subjects studied are similar to the clinic average for this age. In view of the finding that hypoglycaemia was mostly asymptomatic, even at plasma glucose levels of $<2.5 \mathrm{mmol} / \mathrm{l}$, the frequency of hypoglycaemia determined by recording symptomatology alone may an underestimate of the true incidence, reports of hypoglycaemia in children that rely on subjective information provided by parents or on the incidence of coma being unreliable. ${ }^{6}$

Shalwitz et al reported a high frequency of nocturnal hypoglycaemia occurring at $0200 \mathrm{~h}$, with $14.4 \%$ of the values being below 3.3 $\mathrm{mmol} / \mathrm{l}$, while Whincup and Milner reported $34 \%$ below $3.0 \mathrm{mmol} / 1 .{ }^{9}$ Our findings confirm this incidence. Although it is possible that hospital admission may increase the incidence of hypoglycaemia, we endeavoured to minimise this possibility by admitting the subjects as late as possible and ensuring a normal day's activity and exercise. In studies where children were admitted for 48 hours, adjustment cannot be made for differences in dietary intake or exercise and as such do not increase the validity of the study.

We were unable to find any reliable predictive measures for subsequent nocturnal hypoglycaemia. Shalwitz et al showed that subsequent hypoglycaemia may be predicted by a $2200 \mathrm{~h}$ plasma glucose concentration of less than $5.6 \mathrm{mmol} / \mathrm{l}$, a finding supported by Whincup and Milner, who determined that a plasma glucose of $7 \mathrm{mmol} / \mathrm{l}$ was the best predictor. ${ }^{79}$ We found no reliable predictive value in plasma glucose concentrations at any stage preceding hypoglycaemia. Hypoglycaemia was not predictable by age, duration of diabetes, insulin dose, or $\mathrm{HbA}_{1 \mathrm{c}}$. Hypoglycaemia was more likely to be present at 0100 to $0330 \mathrm{~h}$ than at any other time of the night, and as no reliable predictive value could be ascertained, incorporation of early morning (2400-0200 h) blood glucose testing into the monitoring regime is recommended to decrease the incidence of unheralded nocturnal hypoglycaemic sequelae, including convulsions.

The plasma glucose concentrations at breakfast were lower in the children who had been hypoglycaemic during the night than in those who had not. The mean rise in glucose of 2.9 $\mathrm{mmol} / \mathrm{l}$ from the nadir and the persistence of the lower levels at breakfast is consistent with recent reports that the 'Somogyi' effect does not commonly occur in this group. ${ }^{2324}$

In view of the frequency with which hypoglycaemia is asymptomatic at night we tried to determine whether alterations in plasma glucose concentrations have any detectable effect on sleep patterns. Bendtson et al have shown that at plasma glucose levels of $<2.0 \mathrm{mmol} / 1$ there are recordable changes in EEG patterns with increased $\theta$ and $\delta$ activity. ${ }^{14}$ The same investigators have shown that there was a tendency towards a prolongation of the first two rapid eye movement cycles during hypoglycaemic nights. ${ }^{11}$ These observations suggest a tendency to deeper sleep with more profound hypoglycaemia than observed in our study. We have been unable to show any changes in sleep stages during moderate hypoglycaemia, nor any evidence that hypoglycaemia predisposes to increased wakefulness, the number of arousals, or the degree of fragmentation during sleep. By analysing the percentage sleep fragmentation and the number of arousals during hypoglycaemic and non-hypoglycaemic sleep it is possible to 
examine more subtle changes such as restlessness. The lack of any adverse effect on sleep during hypoglycaemia is reassuring in that such episodes would not be expected to result in daytime somnolence. On the other hand the lack of symptomatology with moderate hypoglycaemia might result in the patient failing to arouse and intervene appropriately to prevent more severe nocturnal hypoglycaemia.

To examine the counter-regulatory hormonal response to hypoglycaemia we measured plasma cortisol, growth hormone, and heart rates (as an indirect measure of adrenergic stimulation). The lack of a measurable hormonal counter-regulatory response to blood glucose concentrations of less than $3 \mathrm{mmol} / 1$ is surprising. Jones et al studied adolescents with and without diabetes and found increases in adrenaline and cortisol at this level in diabetic and non-diabetic subjects. ${ }^{21} 22$ Similarly, hypoglycaemic symptom scores rose in the diabetic subjects at blood glucose concentrations below $4.2 \mathrm{mmol} / \mathrm{l}^{22}$ Whether these differences are due to methodology (that is, hyperinsulinaemic clamp induced versus 'spontaneous' hypoglycaemia) or to differences in responses to diurnal and nocturnal hypoglycaemia is open to speculation. Alternatively the lack of a hormonal response may be explained by recent work showing that hypoglycaemia per se will decrease the response to subsequent hypoglycaemia. ${ }^{10}$ It is conceivable that those children who became hypoglycaemic during the study had been hypoglycaemic in the 24 hours before the start and may have been relatively unresponsive to further stress.

In summary, nocturnal hypoglycaemia is a common and usually asymptomatic complication of treatment in adolescents with IDDM. Moderate hypoglycaemia has not been shown to affect sleep architecture adversely. This may explain why severe hypoglycaemia and subsequent seizures are more common at night than during the day. Finally, questions have been raised as to possible differences in hormonal counter-regulation to diurnal and nocturnal hypoglycaemia in this group.

1 Soltesz G. Hypoglycaemia in the diabetic child. Baillieres Clin Endocrinol Metab 1993;7:741-55.

2 Leslie N, Sperling M. Relation of metabolic control to complications in diabetes mellitus. $\mathcal{f}$ Pediatr 1986;108:235-44.

3 Ward CM, Stewart AW, Cutfield RG. Hypoglycaemia in insulin dependent diabetic patients attending an outpatients' clinic. NZ Med $\Im$ 1990;103:339-41.

4 Winter RJ. Profits of metabolic control in diabetic childrenfrequency of asymptomatic nocturnal hypoglycaemia. Metabolism 1981;30:666-72.
5 Macfarlane PI, Walters M, Stutchfield P, Smith CS. A prospective study of symptomatic hypoglycaemia in childhood diabetes. Diabetic Med 1989;6:627-30.

6 Perriello G, De Feo P, Torlone E, et al. The effect of asymptomatic nocturnal hypoglycaemia on glycaemic control in tomatic nocturnal hypoglycaemia on glycaemic con

7 Shalwitz RA, Farkas-Hirsch R, White NH, Santiago JV. Prevalence and consequences of nocturnal hypoglycaemia among conventionally treated children with diabetes mellitus. F Pediatr 1990;116:685-9.

8 Daneman D, Frank M, Perlman K, Tamm J, Ehrlich R. Severe hypoglycaemia in children with insulin dependent diabetes mellitus: frequency and predisposing factors. $\mathcal{f}$ Pediatr 1989;115:681-5.

9 Whincup G, Milner RD. Prediction and management of nocturnal hypoglycaemia in diabetes. Arch Dis Child 1987; 62:333-7.

10 Veneman T, Mitrakou A, Mokan M, Cryer P, Gerich J. Induction of hypoglycaemic unawareness by asymptomatic nocturnal hypoglycaemia. Diabetes 1993;42: 1233-7.

11 Bendtson I, Rosenfalck AM, Binder C. Nocturnal versus diurnal hormonal counter-regulation to hypoglycaemia in type 1 (insulin-dependent) diabetic patients. Acta Endocritype 1 (insulin-dependen

12 Caduff F, Vonesch HJ, Klopfsyein M, Berger W. Nocturnal hypoglycaemia with reference to hormonal counterregulation in type 1 diabetics receiving insulin therapy. Schweiz Med Wochenschr 1989;119:9-15.

13 Bendtson I, Gade J, Thomsen CE, Rosenfolck A. Sleep disturbances in IDDM patients with nocturnal hypoglycaemia. Sleep 1992;15:74-81.

14 Bendtson I, Gade J, Rosenfalck AM, Thomsen CE, Wildschiodtz G, Binder C. Nocturnal electroencephalogram registrations in type 1 (insulin-dependent) diabetic patients with hypoglycaemia. Diabetologica 1991;34:750-6.

15 Pramming S, Thorsteinsson B, Stigsby B, Binder C. Glycaemic threshold for changes in electroencephalograms during hypoglycaemia in patients with insulin dependent diabetes. $B M \mathcal{F} 1988 ; 296: 665-7$.

16 Carskadon MA, Pueschel SM, Millman RP. Sleepdisordered behaviour and behaviour in three risk groups; preliminary findings from parental reports. Childs Nerv preliminary findings

17 Levine B, Roehrs T, Steparski B, et al. Fragmenting sleep diminishes its recuperative value. Sleep 1987;10:590-9.

18 The Diabetes Control and Complications Trial. The effect of intensive treatment of diabetes on the development and progression of long term complications in insulindependent diabetes mellitus. $N$ Engl $₹ \mathrm{Med}$ 1993;329: 977-86.

19 Rechtichaffen LS, Kates RA. A manual of standardised terminology, techniques and scoring for sleep stages of human subjects. Los Angeles: Los Angeles brain information service/brain research institute, University of California, Los Angeles, 1968.

20 American Sleep Disorders Association Atlas Task Force. EEG arousals: scoring rules and examples. Sleep 1992; 15:174-82.

21 Jones TW, Boulware SD, Kramer DK, Caprio S, Sherwin RS, Tamborlane WV. Independent effects of youth and $\mathrm{RS}$, Tamborlane W. Independent effects of youth and poor diabetes control on responses
children. Diabetes 1991;40:358-61.

22 Jones TW, Boulware SD, McCarthy G, Sherwin RS, Tamborlane WV. Enhanced adrenomedullary response and increased susceptibility to neuroglycopenia: mechanisms underlying the adverse effects of sugar ingestion in healthy children. $\mathcal{F}$ Pediatr 1995;126:171-7.

23 Cryer PE, Binder GB, Cherrington AD, Gale EA, Gerich JE, Sherwin RS. Hypoglycaemia in IDDM. Diabetes 1989; 38:1193-9.

24 Tordjman KM, Havlin CE, Levandoski LA, White NH, Santiago JV, Cryer PE. Failure of nocturnal hypoglycaemia to cause fasting hyperglycaemia in patients with insulindependent diabetes mellitus. N Engl $f$ Med 1987; 317:1552-9.

25 Fisher BM, Frier BM. Nocturnal convulsions and insulin induced hypoglycaemia in diabetic patients. Postgrad Med 7 1987;63:673-6. 